\title{
High-profile death throws spotlight on error reports
}

$\mathrm{M}$ anitoba's medical error reporting system — thought to be among the most progressive in the country - has been rocked by allegations that senior regional health officials failed to disclose key facts surrounding the highprofile death of a man who languished for 34 hours in a Winnipeg emergency room without receiving treatment.

Manitoba is generally considered one of the leading jurisdictions in Canada when it comes to laws and protocols for encouraging the disclosure of medical errors, or critical incidents as the provincial government calls them. The province is one of only 3 with legislation that allows doctors to apologize to patients and their families without fear it will be interpreted as an admission of liability. The province also compels health care workers to come forward with details of critical incidents, but protects them from publicity and legal liability.

However, that system has been shaken by the recent disclosure of additional facts surrounding the death of Brian Sinclair, a homeless man who died after spending nearly a day and a half unattended in the emergency room of the Health Sciences Centre, Winnipeg's largest hospital.

The disclosures have elicited concerns that health care officials were trying to bury troubling facts about the case, concerns that some critics believe have eroded other positive aspects of the medical error reporting and investigation system.

"I think what we're seeing now is that if you have bad people running the system, it doesn't matter how good the system is," says Arthur Schafer, director of the University of Manitoba's Centre for Professional and Applied Ethics. "You need both good people and a good system to address a problem like this."

Winnipeg Regional Health Authority officials apologized publicly for the incident and launched 2 internal inves-

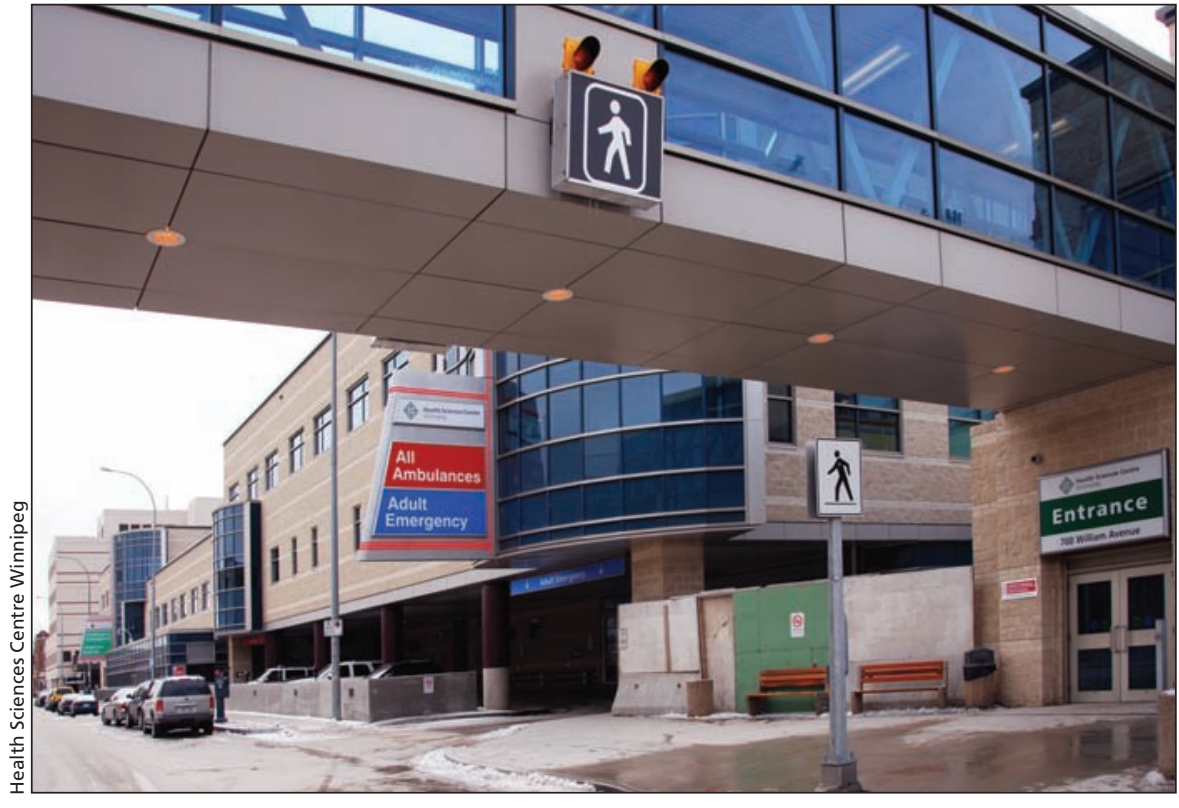

Manitoba's medical error reporting system has been held up as a beacon of progress but that reputation has been dimmed because key fact were initially suppressed in last year's death of a 45-year-old man who spent 34 hours in the waiting room of the Winnipeg Health Sciences Centre.

tigations. However, the authority initially claimed Sinclair, 45, went untreated because he did not approach the triage desk, and thus was never registered in a queue to see a physician. That version of events was challenged in February, when Manitoba's chief medical officer revealed that video surveillance showed Sinclair did in fact approach the triage desk. He also noted that security guards alerted medical personnel that Sinclair's condition was deteriorating, but no one took action.

Authority officials have since admitted that they "misspoke." A coroner's inquest is expected this spring.

Patient safety advocate Leslie Worthington says the case highlights inadequacies in the current system for reporting and investigating medical errors. Worthington says Manitoba has attempted to elicit greater disclosure by promising to keep the identity of individuals and specifics of their actions from the public. But the case demonstrates that the system may not be able to own up to all the mistakes that were made, she says. "The system is not bad, but it's not working. Manitoba is doing a lot of things nobody else is doing [in the area of patient safety and reporting], but there is a lack of leadership that keeps the system from doing all it could be."

But Winnipeg Regional Health Authority Director of Patient Safety Dr. Rob Robson defends Manitoba's critical incident reporting and investigation system as leading edge. "I personally don't see this [the Sinclair case] as a setback. This was totally preventable and it was a tragedy. It simply says that we have lots and lots more work to do."

In 2005, Manitoba introduced legislation that compelled health care workers to disclose facts surrounding a critical incident, and provide full disclosure of all facts to patients and families while still protecting individual health care workers from publicity and legal action. The amendments to the Regional Health Authorities Act and the 
Manitoba Evidence Act also prescribed mandatory internal investigations of all critical incidents.

Yet, in a unique twist, the legislation prevented investigators from revealing the identity of any health care worker involved in a critical incident, and ensured that critical incident reports could not be used in a civil or criminal proceeding.

Robson says the amendments were designed to encourage health care workers to come forward with details of medical mistakes without fear it would end their careers. Health care workers can be disciplined for their roles in critical incidents, but consideration is given if disclosure is made voluntarily.

In 2008, Manitoba followed up the reforms by introducing regular publication of critical incident learning summaries and then became the third province in the country to adopt an apology act that allows any health care worker, including physicians, to apologize for any medical mistake without fear the gesture will be used as an admission of liability.

All provinces suffer from a lack of reporting about critical incidents, Robson says, estimating that of the roughly 1800 critical incidents in the province's hospitals and personal care homes annually, only about 200 are actually reported.

Manitoba's reporting rate, about $14 \%$, is actually considered among the best in Canada. "Those numbers say to me that we're on the right track. But we have a long way to go to get reporting rates to the place it needs to be," Robson says. — Dan Lett, Winnipeg, Man.

DOI:10.1503/cmaj.090528 